\title{
Evolutionary Debunking Arguments Meet Evolutionary Science ${ }^{1}$
}

[This is a preprint; final version forthcoming in Philosophy and Phenomenological Research]

\begin{abstract}
Evolutionary debunking arguments appeal to selective etiologies of human morality in an attempt to undermine moral realism. But is morality actually the product of evolution by natural selection? Although debunking arguments have attracted considerable attention in recent years, little of it has been devoted to whether the underlying evolutionary assumptions are credible. In this paper, we take a closer look at the evolutionary hypotheses put forward by two leading debunkers, namely Sharon Street and Richard Joyce. We raise a battery of considerations, both empirical and theoretical, that combine to cast doubt on the plausibility of both hypotheses. We also suggest that it is unlikely that there is in the vicinity a plausible alternative hypothesis suitable for the debunker's cause.
\end{abstract}

\section{Introduction}

That the evolutionary origins of humans' moral sensibilities may undermine moral realism is a tantalizing prospect that has been attracting a steadily growing stream of attention (Vavova, 2015). Evolutionary Debunking Arguments (EDAs) attempt to exploit the evolutionary etiology of our moral psychology to systematically undercut the grounds we supposedly have for holding (realistically construed) moral beliefs. There are different EDAs out there, with some important distinguishing details. But their general common structure can be helpfully represented by means of the following compact schema (Cf. Kahane, 2011):

Causal premise One's belief that $p$ (for a moral $p$ ) is explained by evolution through natural selection.

\footnotetext{
1 The authors are listed in alphabetical order. For their detailed and extremely valuable written comments on earlier drafts, we'd like to thank Dan Baras, Alessandro Di Nicola, David Enoch, Uri Leibowitz, Thomas Pölzler, and an anonymous reviewer. Many thanks also to an audience at the annual meeting of the European Normativity Network in Oslo for very helpful discussions of material from this paper.
} 
Epistemic premise Natural selection is an off-track process with respect to (mind-independent) moral truths.

\section{Therefore,}

One's belief that $p$ is unjustified (at least if it aims at tracking mind-independent moral truths).

The epistemic premise is supported in something like the following way. Natural selection explains the traits of organisms by showing how they contributed to the survival and reproduction of their ancestors. It stands to reason that an organism's survival and reproduction can be positively affected by its having moral beliefs. For example, if the organism believed it should reciprocate altruistic behavior, refrain from incest, or care for its offspring, it would tend to be more strongly motivated to act accordingly and thereby increase its chances of survival and reproductive success. But such evolutionary advantages would seem to accrue to an individual whether or not her beliefs happen to be (mind-independently) true. It is this truth-indifference of evolutionary explanations of human morality that purportedly has debunking implications. Advocates of EDAs claim that, if the origins of our moral beliefs are explained in a truth-indifferent fashion, this systematically questions the grounds on which we hold those beliefs - or, at least, it does so if those beliefs are understood as tracking mind-independent truths, as the realist suggests. Hence the conclusion of the schematic EDA above.

In this paper, we investigate how serious a threat EDAs actually pose to ethical realism. Our approach is novel in focusing on the causal premise, which has received considerably less attention compared to the epistemic premise or the validity of the argument. While different EDAs provide outlines of evolutionary genealogies of human morality, few writers attempt to elaborate a detailed 
story, and even fewer engage in assessing the plausibility of such stories. ${ }^{2}$ One possible explanation for this trend is articulated by Kahane (2011: 111): "It is important to see that it does not matter here whether any particular evolutionary explanation is true. What matters is that some such story is likely to be true." And in a similar vein, Vavova admits that EDAs rely on controversial empirical claims from evolutionary psychology but suggests that "both sides should acknowledge this and move on ... [W] hile it is important that this argument is empirical, the particular empirical claim is not important. It is replaceable and, anyway, not philosophically interesting." (2015: 104)

For some purposes, it may be appropriate to abstract away from the details of how natural selection explains our moral beliefs, but only of course on the assumption that some such explanation is in fact available. Assessing this crucial assumption and its bearing on the debate is our principal task in what follows. The upshot, to anticipate, is unfavorable to the aspiring debunker: We point to a battery of considerations, both empirical and theoretical, that combine to cast doubt on the availability of a satisfactory evolutionary explanation, suitable for the debunker's aims. Specifically, in sections 2 and 3 we will look at the evolutionary hypotheses underwriting the two most prominent EDAs - those put forward by Richard Joyce and Sharon Street. Then, in section 4, we will suggest, albeit tentatively, that there is no plausible alternative hypothesis that Street or Joyce could appeal to to vindicate their respective debunking projects.

Before plunging in, however, one important assumption guiding our discussion should be made explicit. Whatever causal hypothesis the debunker opts for, we assume it must involve biological evolution, specifically via natural selection. ${ }^{3}$ This is informed by our understanding of EDAs as raising a novel and distinctive challenge, in part at least by proposing a specific kind of debunking, grounded

\footnotetext{
${ }^{2}$ Notable exceptions to this trend are Machery and Mallon (2010), Fraser (2014), Fitzpatrick (2015), Isserow (2018).

3 White (2010: 589-595) and Bedke (2014: 104) downplay the significance of a specifically evolutionary etiology.
} 
in evolutionary biology. This understanding serves to distinguish EDAs from traditional skeptical challenges, lending them added credibility by comparison. As Vavova puts it, evolutionary debunkers "do more than raise the possibility of error. They make that possibility probable. On any plausible view, such testimony from respected [scientific] professionals should worry us" (2015: 105). A related point demonstrating a dialectical edge EDAs have over more traditional skepticism has recently been made by Joyce (2016a: 158). He points out that one common response to the traditional (moral) skeptic is unavailable against the evolutionary debunker:

It has not infrequently been claimed against the moral skeptic that one's confidence in fundamental moral intuitions must be far more robust than one's confidence in any obscure philosophical argument ... An EDA has the strength to overturn this comparison, by presenting evidence to account for those fundamental moral intuitions - which can account even for their persuasive felt quality - that is compatible with their falsehood (in the sense that even an error theorist can accept the evidence).

The specifically evolutionary flavor of the causal premise is central also to some prominent realist responses to EDAs (e.g. Copp, 2008; Wielenberg, 2010; and Carruthers and James, 2008), which work by proposing alternative evolutionary hypotheses that are meant to be compatible with the realist's commitments.

Still, one might concede the significance of invoking a specifically evolutionary etiology yet resist our plea to scrutinize more carefully its credentials. For one may suggest that the debate can anyway be conducted on purely bypothetical grounds. That is, perhaps the causal premise could be construed as stating merely that one's (moral) belief that $p$ might be explained by natural selection (perhaps adding a specific hypothesis about how this may have occurred); the conclusion of the argument would then 
correspondingly state the conditional claim that if one's belief that $p$ is indeed explained by natural selection, then it is unjustified. This exercise is not pointless, it might be added, since after all, it is not as though the evolutionary hypothesis is ever likely to be conclusively and incontrovertibly refuted by its detractors - evolutionary hypotheses rarely are.

We accept that the debate can be conducted in this manner. But there is also much to be said for the alternative strategy we employ here. First, the two strategies are in fact compatible and may be usefully combined. Moreover, running the argument only in its hypothetical form undermines some important dialectical advantages. For example, it will no longer be the case that, as Vavova suggests, the 'respected professionals' verdict supports the debunker's project. Finally, and relatedly, stating the argument purely hypothetically prevents us from assessing how urgent the challenge to realism is: Does evolution actually undermine realism or does it merely hold the potential of doing so? The rather central place EDAs occupy on the philosophical agenda seems to stem at least partly from the actual, hence urgent, threat to realism they represent.

For these reasons, we will assume that EDAs present a distinctive and novel challenge, one underpinned by a hypothesis about the actual origins of human morality, and examine whether they succeed in doing so. We begin in the next section by looking at Richard Joyce's influential version of the argument.

A final preliminary remark concerns the scope of the relevant evidence. Quite generally, what counts as data about $\Phi$ inevitably depends on assumptions about the nature of $\Phi$. Morality is no exception (Pölzler, 2018). The way in which one conceptualizes the moral domain - is it concerned primarily with harms and benefits? Does it include private sexual behaviour? Religious practices? Etc. - will affect what one takes as pertinent evidence for and against specific hypotheses about its evolution. As we say, this sort of issue arises quite generally whenever a theoretical hypothesis is 
evaluated empirically. But it may appear especially acute in the present context, as views about the nature and scope of morality vary considerably, both among philosophers and (arguably even more so) among the folk. ${ }^{4}$

Our strategy for handling this difficulty is to try and broaden the scope of the evidence we consider. Thus we look at data pertaining to what counts as core moral concerns by anyone's lights, such as interpersonal commitments and the infliction of bodily harms; but we also consider data to do with practices that some but not all societies moralize, such as sexual conduct (specifically, incest; see sec. 3.2.3). In this way, we hope to cover evidence that is pertinent on a variety of views about the scope of the moral domain. (We comment on specific manifestations of this issue below, where it arises).

\section{Joyce's causal premise}

\subsection{The 'moral sense' hypothesis}

Joyce's hypothesis pertains to how humans developed what he dubs a 'moral sense' - the capacity to make moral judgments as such, irrespective of their content (2006: 108-142). He develops an account of the selection pressures that led to the evolution of humans with a moral sense. In a nutshell, it runs as follows. First, along with many others, Joyce supposes that the ability to cooperate with conspecifics is key to humans' evolutionary success. But, he notes, while behaving cooperatively is advantageous in the long run, egoistic, non-cooperative actions often present more immediate benefits. The fruits of cooperation tend to be in the distant and intangible future, whereas short-term

\footnotetext{
${ }^{4}$ Debates over the nature of morality may be relevant to the assessment of EDAs in another, related, sense. According to Joyce (2016b: 13) EDAs 'have teeth' only when combined with metaethical arguments that successfully undermine a realist-friendly moral epistemology. We thank an anonymous reviewer for raising this point.
} 
temptations are readily apparent. Joyce holds that viewing actions, especially cooperative actions, as morally required makes succumbing to short-term temptations less likely, cementing a cooperative social structure. To this end, he suggests, evolution forged a tight link between moral judgment and moral emotions, the latter supplying a forceful motivational power. Morality acts as a 'motivational bulwark' (ibid, 121) against weakness of will, and this enabled ancestral humans to abide by their longterm interests and resist the lure of short-term benefits.

Sure enough, the moral sense hypothesis nowhere invokes moral truths or facts, in line with the epistemic premise. This renders moral truths explanatorily specious, according to Joyce, and hence discredited. His conclusion is moral skepticism - a central component of the moral fictionalism he is well known for advocating (Joyce, 2005).

A key feature of Joyce's hypothesis is the idea that morality is cognitively distinct-moral thinking has a special function and a distinct cognitive role: "The hypothesis is that natural selection opted for a special motivational mechanism for [certain forms of cooperative behavior toward one's fellows]: moral conscience." (2006: 111). It is not hard to see why Joyce should want his EDA to target exclusively the moral domain, in contrast to other normative domains. Consider for example epistemically normative beliefs. And notice that an EDA such as Joyce's, which aims to establish moral skepticism, would, if generalized to epistemically normative beliefs, run the risk of self-undermining. For EDAs themselves appeal to scientific evidence from evolutionary psychology, and draw lessons about what we should (not) believe regarding the workings of natural selection (cf. White, 2010: 592.) Indeed, the very idea of skepticism about epistemic normativity seems 'self-stultifying' (Kahane, 2011: 117): An argument advancing epistemic skepticism puts forward a conclusion that by its own lights should not be believed. Furthermore, if wholesale normative skepticism is on the line, this raises the stakes considerably; it is a position that is much harder to accept and hence much harder for the skeptic to 
establish. It thus seems clear that a Joyce-style EDA had better guard against implying sweeping normative skepticism. ${ }^{5}$

\subsection{Assessing Joyce's hypothesis}

2.2.1 The threat of over-generalizing. Recall that Joyce focuses on motivational challenges arising in the context of social cooperation. As a preliminary source of doubt, let us note that it is unclear why the realm of social relations, and of cooperation in particular, should present unique motivational challenges, giving rise to a 'special motivational mechanism'. After all, there are other contexts where conflicts between short-term temptations and long-term interests arise, and where the potential price (in terms of biological fitness) for succumbing to such temptations is high.

Consider, for instance, the need to invest in long term projects like building shelter or storing food for times of inclement weather. These are situations where short-term temptation may equally impede more advantageous long-term endeavours. Applying Joyce's reasoning, we thus seem entitled to hypothesize the existence of parallel 'motivational bulwarks' in the form of non-moral normative beliefs - e.g. that the impending inclement weather is reason to start storing food (prudential normativity); or that the dropping temperatures are reason to believe that inclement weather is impending (epistemic normativity) evolving to guard against damaging practical and epistemic irrationality. Indeed, even the phenomenology, which may be thought to add to the initial plausibility of Joyce's hypothesis, has a close parallel here, at least in the prudential case: It is often awareness that e.g. one really shouldn't have

\footnotetext{
${ }^{5}$ Joyce himself has a further reason to avoid general normative skepticism. His own fictionalist error-theoretic view recommends, on prudential grounds, that we preserve our ontologically bankrupt moral discourse (Joyce, 2005). But if wholesale normative skepticism prevails, this recommendation would obviously have to be discarded alongside all other normative judgments.
} 
another piece of pie which prevents one from succumbing to that temptation. ${ }^{6}$ But if this is correct, then Joyce's causal hypothesis would generalize beyond the moral domain, impinging on the prudential and the epistemic as well - a result he is (and should be) keen to avoid, as explained above.

\subsubsection{A psychologically real, (near-)universal distinction?}

Moving on, we note that one important

source of evidence for adaptation is that the purportedly adaptive trait is found universally. Moreover, if a trait exhibits a universal pattern of development - such as appearance at a particular age or passage through a set sequence of stages - this is typically seen as a fairly strong indicator of adaptation. Conversely, the lack of universality, in development and in adulthood, is evidence for lack of adaptation. $^{7}$

In this vein, Joyce cites the existence of moral codes in diverse cultures as evidence for universality. More systematically, he relies on findings from developmental psychologist Elliot Turiel, who argued that all children distinguish moral from social conventions, and that they do so at a relatively young age. In this context, moral norms are defined as those that regulate the affliction of harms and violation of rights; are typically seen as serious concerns (often overriding others); and are justified in an authority-independent way, usually generalizable to other times and places. In contrast, conventional norms have a more varied subject-matter, are seen as less serious, and are typically justified by appeal to a social institution or a specific authority figure (parent, teacher etc.). Turiel and his students found that American children around the age of three can distinguish morally sanctioned

\footnotetext{
${ }^{6}$ It may be less clear that the phenomenology supports our case when it comes to the motivational effects of epistemic normativity. Perhaps potential lapses into wishful thinking and self-deception are not typically overcome by the felt force of what the evidence implies. We are unsure. But we are anyway reluctant to place too much weight on phenomenological considerations. After all, it may be that the relevant motivational mechanism is so ingrained in us that we no longer feel the psychological conflicts as vividly as our ancestors perhaps did.

${ }^{7}$ See Machery \& Mallon, 2010 and Polzler, 2015 for further discussion.
} 
acts from conventional ones, and suggested that the distinction remains robust over the lifetime of individuals and across different educational backgrounds (Nucci \& Turiel, 1978; Nucci, 2001; Tisak \& Turiel, 1984; Tisak, 1995; Smetana, 1981).

However, subsequent work has cast doubt over Turiel's initial findings, including both their crosscultural application and their developmental characteristics. In a 1985 study, Richard Schweder reports that actions related to food, sex, clothing and gender relations were typically moralized by Indians, while treated as conventional by Americans. And in a series of well-known studies, Jonathan Haidt and colleagues (1993) have shown that judgements about whether a certain norm counts as moral or conventional vary between cultures. These differences were observed when subjects were presented with dilemmas pertaining to sexual conduct, ethnic and national identity, nutrition, and other matters. Brazilians, for instance, classified scenarios detailing unusual sexual conduct (e.g. intercourse with a store-bought chicken corpse prior to cooking and eating it) as immoral, whereas Americans evinced aversion to such acts but regarded them as merely unconventional. Similar differences were found across people of differing socio-economic standing. Other studies have identified norms - e.g. some kinds of etiquette norms - that do not fall neatly into either the moral or the conventional category (e.g. Nichols, 2002, 2004; Nisan, 1987). And some recent work suggests that even with respect to norms pertaining to serious bodily harm, the moral $\backslash$ conventional distinction runs into trouble. Thus Kelly et al. (2007) found that subjects tended to view actions involving whipping, prisoner abuse, and even slavery in authority-dependent terms. ${ }^{8}$

Turiel's developmental claims have also been undermined by experimental results. As reviewed in Gabennesch, 1990, a range of studies has found that a moral/conventional distinction appears at a different, and often much later age than Turiel suggested - in some studies, as late as late-teens. This

\footnotetext{
${ }^{8}$ This is one place where the question highlighted earlier, regarding the scope of the moral domain, becomes
} salient; see sec. 1. 
suggests that acquaintance with the distinction may well be a product of cultural-environmental influences, with a limited role for biological ones. Indeed, Gabennsech discusses various environmental cues that could help children learn the distinction, obviating the need for an innate biological endowment. (See Machery and Mallon, 2010, \$3.3.3 for doubts about other kinds of purported developmental evidence in this context).

Put together, these findings suggest three interrelated conclusions. First, they cast doubt on the universality of the moral/conventional distinction, and consequently on whether we have been endowed by evolution with a distinct moral sense. Although it is conceivable, consistent with all cited findings, that such a distinction plays a stable role in our moral psychology, the fact that the contours of the distinction shift so markedly across and within cultures, and the fact that certain kinds of violations do not fall on either side of it, make that possibility unlikely. Second, the findings suggest that there is no characteristic developmental trajectory, especially not an early, innate-endowmentdriven emergence of the moral/conventional distinction, thereby questioning once again any claim to adaptivity. Lastly, the findings show that the moral category, even if stable and prevalent, does not exhibit the subject matter we'd expect on the basis of Joyce's account. For recall that for Joyce, the moral sense functions as a bulwark against short-term temptations that, if acted upon, would damage social order and cooperation. But many of the transgressions that were perceived as moral in the studies cited are not of this sort: They involve etiquette, (private) sexual conduct and other matters that do not seem to involve social structure and cooperation. Thus, work on the moral/conventional distinction seems to undermine, rather than support Joyce's story.

2.2.3 Common mechanisms? If moral cognition evolved to serve a specific function, as Joyce suggests, then one may provisionally expect it to be subserved by a dedicated neuro-cognitive 
mechanism (potentially several related ones). To be sure, the existence of dedicated mechanisms isn't a necessary implication of Joyce's hypothesis: It may be that natural selection co-opted one or more existing mechanisms, for instance. But dedicated functions often are subserved by dedicated mechanisms, and the discovery of dedicated mechanisms is a telltale sign of a specialized function. Therefore, the presence of such a mechanism in the case of human morality should make us more confident in Joyce's hypothesis - and conversely, its absence should decrease our confidence.

A variety of studies examine the pattern of activation of brain regions during the formulation of moral judgements (mainly via fMRI), and nearly all of them find multiple areas to be involved (SinnottArmstrong \& Wheatly, 2012). Specifically, several studies have identified divergences within the class of moral judgments - cases where distinct types of moral judgement appear to involve different neural substrates. Let us describe briefly several results in this vein.

Moll et al. (2005) presented subjects with moral dilemmas in which they could either license or oppose donations to a certain charity, whose work is associated with a morally contentious issue (such as war, abortion, gender equality and the death penalty). They then looked at the difference in brain activity between subjects who opposed donations to such charities and those who were in favor of donating. The former appear to be acting on a probibition. The latter, in contrast, presumably acted on a positive requirement (or alternatively a permission). In these two groups, moral judgements were found to be associated with activation in distinct brain regions. While some overlap was observed, no region was found to be activated in all and only moral judgments.

Parkinson et al. (2011) zoomed in on the category of moral prohibitions. They constructed a set of vignettes describing scenarios designed to evoke either of three responses: Disgust (an emotion often associated with negative moral judgement and much studied in this context), a judgement of the portrayed act as harmful, or a judgement that the act was dishonest. They asked participants to 
explicitly state whether they viewed the acts described in the vignettes as morally wrong, harmful and/or dishonest, and compared brain activity in response to such scenarios against one another and against morally neutral scenarios. As Sinnott-Armstrong (a co-author on the Parkinson et al. study) and Wheatley state: "None of [the increased activity] areas were found to be common and peculiar to all and only judgements of moral wrongness" (2012: 368).

Another set of results that suggest a similar conclusion comes from the work of Joshua Greene. His research is well known to philosophers as it engages with the distinction between deontology and consequentialism. Greene's basic contention is that these two outlooks in fact stem from two distinct cognitive systems, each sensitive to different stimuli. One system, associated with deontological processing, is primarily affect- (or emotion-) driven, while the other system, associated with consequentialist processing, is “colder”, driven primarily by reasoning-like processes. Greene et al.'s 2001 imaging study is perhaps the best-known result on this theme. But Greene's subsequent work has provided further evidence for his central claim (Greene, 2014).

Now, since this work is controversial, let us be explicit regarding our use of it. First, Greene has suggested that his results have normative significance - specifically, that they provide support for consequentialism over deontology (Greene, 2014). It should be clear that we do not rely on this idea. Second, some philosophers have criticized Greene for the way in which he operationalizes consequentialist and deontological judgements (e.g. Berker, 2009). We need not take a stand on this issue. From our point of view, all that matters is that Greene's results, especially when taken as a whole to include data beyond the initial fMRI study, strongly suggest that the mechanisms underlying moral judgement are heterogeneous. ${ }^{9}$

\footnotetext{
${ }_{9}^{9}$ Greene's results also cut against Joyce's hypothesis in another way, by suggesting that at least some significant moral judgments are not emotion-based. This can be seen to weaken the strong link Joyce sees between moral judgements and emotion-based motivation.
} 
Thus, several sources of empirical evidence tell against Joyce's version of the causal premise. First, his hypothesis regarding the selection pressures that shaped moral cognition seems to generalize beyond the moral domain. Moreover, Joyce's attempt to buttress his hypothesis by appeal to work on the moral/conventional distinction is belied by the state of play on this distinction. Lastly, existing knowledge about the neurocognitive mechanisms underlying moral cognition casts doubt over the idea that moral cognition is a unified category, as Joyce's hypothesis seems to imply.

\section{Street's causal premise}

\section{1 'One enormous factor in shaping the content of human values'}

The second prominent EDA we shall focus on is Sharon Street's. Her argument differs from Joyce's in several important ways. Street (2006) argues that our dispositions to form the moral beliefs we tend to form were shaped by selection pressures which, for reasons already explained, were very likely off-track with respect to moral facts. This would make it an extraordinary coincidence if such beliefs nonetheless happened to align with moral facts, as the realist maintains. A further difference from Joyce is that Street does not take this to support moral skepticism. For she believes there is a positive, superior anti-realist account of moral beliefs, which is not threatened by worries about misalignment between moral truth and moral judgement.

For present purposes, the most important distinguishing feature of Street's EDA is her version of the causal premise. It targets the content of our moral beliefs rather than our capacity to form them - it is what we tend to believe that bears the mark of evolutionary influence. Moreover, this influence is deep and wide-ranging - 'thoroughly saturating' our system of evaluative judgements (Ibid, 114). The tremendous influence of natural selection is borne out, according to Street, by the striking 
common tendency of extant humans to make moral judgments which would have reinforced the motivation to act in fitness-enhancing ways. Such judgments include, for instance: (1) "The fact that something would promote one's survival is a reason in favor of it"; (2) "The fact that something would promote the interests of a family member is a reason to do it"; and (3) "The fact that someone has treated one well is a reason to treat that person well in return." (Ibid, 115)

Now Street acknowledges the implausibility of supposing that "the acceptance of a full-fledged evaluative judgement with a given content ... is a genetically heritable trait" constituting a biological adaptation in itself (119). Rather, her idea is that natural selection has had an 'indirect' (yet no less

tremendous for that) influence on our judgements, by having direct influence over our "proto" or "basic evaluative tendencies [which], in their turn, have had a major influence on the evaluative judgements we affirm” (120). Street asserts that such judgments as (1)-(3) above are common "across both time and cultures..." (115), though she does not provide evidence for this assertion. She then briefly suggests that judgments such as (2) are explained by appeal to the theory of kin selection, while judgments such as (3) can be explained by appeal to the theory of reciprocal altruism. We proceed to evaluate this picture.

\subsection{Assessing Street's hypothesis}

It is worth noting at the outset the significant discrepancy between Street's reasoning and what seems to be the mainstream view in the relevant parts of science - evolutionary theory, moral psychology, and biological anthropology - as well as in philosophical discussions that border on the science (Ayala, 2010; Kitcher, 2011; Lewens, 2015; Skyrms, 2003; Sterelny, 2012). Street supposes that the origins of moral content are predominantly biological. She does allow that extra-biological factors have had some role to play in shaping the content of our moral judgments; but she views the 
biology as the overwhelmingly influential factor. The scientific and philosophical consensus, in stark contrast, tends to identify culture as the predominant driver of the content of moral norms, according only a minor role to biology. To be sure, many view the cultural process in question as a kind of evolution - but they have in mind a process of 'cultural evolution', one that shares broad structural similarities with biological evolution, but involves social learning rather than genetic inheritance and proceeds at a much faster pace and in a more culture-specific way.

There are powerful reasons for siding with the majority view of scientists and philosophers over Street's. A central one is the pace of moral change: Biological evolution is a slow process, proceeding incrementally over many generations. Moral change, in contrast, can occur over much shorter time spans. Thus attitudes surrounding such issues as slavery, women's standing in society, and the rights of gay people have changed dramatically in recent centuries, even decades. In evolutionary biological terms these are mere blinks of an eye. If these cases are representative, then the pace of moral change does not match what we would expect from a process driven by natural selection. Patterns of crosscultural variation (illustrated below) provide another reason for identifying culture as the principal driver of moral change. So the possibility that moral change is driven by cultural rather than biological dynamics is well worth keeping in mind.

Could Street abandon her causal premise and opt for a cultural-evolutionary hypothesis instead? We return to this question in section 4. First, let us look at Street's actual claims more closely.

3.2.1 A preliminary worry. As noted, Street illustrates the purportedly huge influence of natural selection by citing particular beliefs such as (1)-(3) above, which clearly seem evolutionarily advantageous. But one might suspect that these examples have been cherrypicked. To see why, consider two classes of moral beliefs Street does not mention. The first class consists of pervasive 
beliefs for which it is either unclear what evolutionary advantage having them could afford; or worse, they seem downright disadvantageous from an evolutionary perspective. Instances belonging in this class are (among others) the belief that one should avoid eating meat; that racism is deplorable; that men and women deserve equal treatment; that the interests of future generations should be safeguarded; and so on. It is hard to see what advantages such beliefs could provide. It would be strained, to say the least, to attempt to explain them by appealing to reciprocal altruism, kin selection, or an increased likelihood of survival (cf. Parfit 2011, vol. II: 534-542; Huemer, 2016). The second class consists of beliefs that certainly seem fitness-enhancing but are far from pervasive. Instances belonging here are the belief that philandering is permissible; that using contraception is prohibited; that killing one's stepchildren is permissible (or even required); and so on.

Street has a reply ready to this charge. Her view, recall, is that natural selection directly influenced our "basic evaluative tendencies", which in turn have deeply influenced the judgments we tend to affirm. But she allows that "other causal influences can shape our evaluative judgements in ways that make them stray, perhaps quite far, from alignment with our more basic evaluative tendencies" (2006: 120). The other influences Street has in mind here are presumably cultural, as well as the use of reflection, among other things. It is the contrary influence of these non-biological factors which explains, she would argue, the prevalence of beliefs in our former category and the scarcity of beliefs in the latter.

We are not yet in a position to fully assess this response to the cherrypicking worry. What is clear is that its tenability turns crucially on Street's picture of a 'core' of basic tendencies which represents our evolutionary endowment and gives rise to dispositions to affirm particular moral judgments. In the following subsections we aim to undermine this picture by questioning the thought that such dispositions have been selected for. If our arguments there succeed, then Street has no response to the cherrypicking objection, either. Our (preliminary) point here, which should be kept in mind 
throughout, is that even the initial intuitive impetus to accept Street's picture is readily resistible. There is a good range of beliefs, as illustrated above, that either do not bear the marks of evolutionary influence, or else do (or rather, would) bear that mark but are not widespread. Focusing on those beliefs instead would lead one initially away from hypothesizing the existence of basic evaluative tendencies instilled in us by natural selection (and perhaps towards a predominantly culture-based view, or some form of middle ground). ${ }^{10}$ We proceed to examine whether Street can adduce compelling evidence that her picture is superior to the alternatives.

3.2.2 Theoretical models. Street alludes to theoretical models of biological altruism to buttress her view of the origins of moral beliefs. Since she does so briefly and without spelling out specific explanations, we will look at the general question of whether it is plausible that such models explain human moral beliefs. Street appeals to two types of models: Regarding beliefs that pertain to partiality towards kin (e.g. "The fact that something would promote the interests of a family member is a reason to do it"), she posits a kin-selection based explanation. Regarding altruistic behaviors and norms of reciprocity, she appeals to the theory of reciprocal altruism. Let us take these in turn.

Kin selection is the idea that behaviors that are differentially directed at organisms who share the genes responsible for said behaviors may get selected, even if they harm the behaving individual (Bourke, 2011). If I make a sacrifice for those who share my genes, then insofar as my actions promote their survival and reproduction to a greater extent than they harm my own, over time our shared genes will spread. It is important to note that the theory translates this intuitive idea into mathematical

\footnotetext{
10 At some points, Street talks as if the relationship between the biological and the cultural is to be viewed in temporal-historical terms: Evolution brought us a certain distance and culture took over from there. Doubts can certainly be raised about this sort of picture. In fact, it seems much more plausible to view the biological and the cultural as acting - and changing - in tandem. But since Street does not explicitly advance a view of the relationship between culture and biology, we will not pursue this point any further.
} 
language, the core of which is Hamilton's rule: $r B-C>0$, where $C$ and $B$ are, respectively, the cost (to the altruist) and benefit (to the recipient) of an altruistic act, and $r$ is the degree of genetic similarity between altruist and recipient. The quantitative aspect matters because even when interactants are very closely related, as in cases of parent and offspring, $B$ and $C$ may be such that instead of altruism, Hamilton's rule predicts conflict (Trivers, 1974). ${ }^{11}$ Thus, kin selection theory does not always predict behaviour guided by a belief about the significance of the interests of family members. A bare appeal to kin selection does not cut much ice. ${ }^{12}$

As noted, however, Street appeals to kin selection only to explain some of our moral beliefs, relying on the theory of reciprocal altruism to account for other cases. Models that fall under the latter heading apply beyond kin. Their key idea is that if individuals act altruistically only towards those who have acted altruistically towards them, then the benefits of altruism would be bestowed upon altruists, leading to their selection. In models bearing out this general idea, the problem of altruism is usually represented by means of a prisoner's dilemma or a similar pairwise conflict of interest situation, such as a bargaining game (Trivers, 1971; Skyrms, 2003; Okasha, 2013). Speaking roughly and generally, reciprocal strategies such as Tit-for-Tat - cooperate first and then do what your counterpart did in the previous interaction - tend to do well in such settings (Nowak, 2006, Ch. 5).

However, there are several concerns about the scope and character of these models, specifically as they pertain to human morality. For one thing, virtually all models in this area deal with pairwise interactions between a single altruist and a single beneficiary. But moral precepts often concern situations with more persons involved. Models of reciprocal altruism can, in principle, be extended to

11 This should be distinguished from the (biologically controversial) phenomenon, so-called 'spite', where interactants behave antagonistically depending on how closely related they are (i.e. depending on the value of r) relative to the average relatedness of individuals in the population.

12 Note also that an appeal to kin selection theory requires that moral beliefs exhibit a significant genetic basis. There is not much evidence on this score, but some studies of heritability of moral and political attitudes exist, showing mixed results (Israel et al., 2015; Smith et al., 2016). 
n-person problems. But such models are hard to solve, mathematically speaking, and it is not clear that they yield results that are consistent with those of two-person models (Weibull, 1995). Furthermore, models in this area make a host of idealizations about the character of interactions relevant to morality. For instance, interactants are often assumed to be identical in all but (potentially) their strategy in the game. They thereby ignore the role of social hierarchies, facts pertaining to the origin of contested benefits, and other features that seem to play a significant role in moral judgement (Levy, 2011). Thus, while reciprocal altruism may be able to explain simple cases of quid-pro-quo concerning pairs of interactants in highly idealized settings, it is unclear that it applies to more realistic scenarios.

There is also a more overarching problem with models of altruism. This is a point that applies to reciprocity-based models as well as kin selection and other approaches. The problem is that, even if fully successful and assuming they cover the full range of morally-relevant scenarios, these models are designed to explain altruistic behavior, they do not concern beliefs, concepts or other mental items. This fact is often noted in discussions of the problem of altruism in the philosophy of biology (Okasha, 2013). There, it is common to distinguish between biological altruism, a notion defined by the respective behaviors of the altruist and the beneficiary, and their consequences for reproductive success alone; and psychological altruism, i.e. behavior that stems from other-regarding motives. It is often emphasized that models in evolutionary biology have little to say about the psychological basis of altruism (where such a basis exists, e.g. in humans).

Now, one may attempt to devise evolutionary scenarios that begin with biological altruism and then add on an extra psychological layer. Street at one point hints at such a sequence, but does not elaborate (2006: 118). Absent details, it is impossible to assess how compelling such a story might be. (For example, what motivational role is left for the creature's judgment to play, if its behavior is already in line with the contents of the judgment?) As matters stand, models in this area do not apply to beliefs 
and motivation but rather explain behavior alone. Hence it is unclear how they could support Street's hypothesis.

3.2.3 Universal judgments? Recall that when discussing Joyce's causal premise, the question of universality concerned the existence of moral judgment as a sui generis psychological kind. In Street's case, the question becomes whether there are, as she suggests, "deep and striking patterns, across both time and cultures, in many of the most basic evaluative judgements that human beings tend to make" (2006: 115). If such widespread patterns in the content of moral beliefs can indeed be found, this would constitute evidence that the origins of said content can be traced to natural selection (for caveats concerning appeals to universality, see sec. 2.2.2, above).

We begin by briefly looking at incest taboos. Street does not mention this example, but it has been quite widely discussed, and it seems a very good candidate for an evolutionarily determined norm, since the costs of incest are biologically straightforward. However, as Prinz (2007) argues, incest taboos are universal only in a very minimal sense - virtually all societies have some such prohibition, but they differ markedly with respect to which relatives are included, and the circumstances under which incest is prohibited. Moreover, the biological mechanism long believed to underlie incest avoidance, the so-called Westermarck mechanism in which children are thought to develop a sexual aversion towards individuals with whom they interact closely at a young age, has recently been questioned on empirical and theoretical grounds (Shor \& Simchai, 2009). Thus, even with a very good candidate for a moral universal, viz. incest taboo, questions arise.

Here a worry we commented on earlier (see sec. 1) regarding the purview of morality may arise. Specifically, one might wonder whether incest is in fact a morally relevant category, and hence whether we should be assessing empirical evidence pertaining to it in the present context. No doubt views on 
this question differ. While very many societies do moralize incest in some shape or form, certainly not every individual would agree (for discussion of the scope and ways in which incest is moralized, see Thornhill, 1990, 1991). For this reason, we do not place anything like full weight on the case of incest. Rather, incest is mentioned as one serious candidate for a moral universal, which has been studied empirically and comes with a straightforward evolutionary rationale, alongside various other such examples discussed below. In this way, we aim to cover norms that are considered properly moral on a range of different views about the true scope of the moral domain. ${ }^{13}$

Consider, then, another example: Prohibitions against harm. In a very broad sense, some kind of prohibition against harm is present in very many societies, perhaps every society. But that seems much too thin to ground a universal norm nor does it provide much support for a hypothesis based in natural selection, as we shall now argue. Across societies, one finds norms that vary considerably with respect to the kind of persons one may harm. Some societies permit harming only members of out-groups; others permit members to harm some members of the in-group, such as women or disabled people. Societies also vary in the contexts and degrees of harm permitted - from ceremonial and other attenuated forms of harm, through warfare, to cannibalism. (Prinz, 2007; Sripada, 2007; Machery and Mallon, 2010). Now, it may be possible to come up with very 'thin' harm norms that may capture such extreme variations (e.g. perhaps 'do not harm others indiscriminately'). But there is no empirical evidence for such thin universal norms, as far as we are aware. Furthermore, there is no need to wield the heavy machinery of natural selection to explain the existence of such a thin norm as 'do not harm others indiscriminately'. It might just as well represent a "good trick" (to borrow a term from Dennett, 1995) - a salient solution to a recurring problem, which intelligent agents are likely to converge on. (Compare covering one's head in the sun. This might be a universal type of behaviour in humans, but

\footnotetext{
${ }^{13}$ We thank an anonymous reviewer for highlighting this issue.
} 
there is hardly any pressure to call upon natural selection to account for its emergence). Thus, there does not seem to be a substantiated case for universality in norms pertaining to harm.

Let us consider a potential concern, raised by an anonymous reviewer. S/he notes that the universality of prohibitions against harming may be underwritten by a more complex relation to observable data than we seem to allow. For instance, on a view that draws a Chomsky-inspired analogy between linguistic and moral competence, morality is seen as universal at the level of "deep" grammar, while differing superficially at the level of overt "surface" structure (Hauser, 2006; Mikhail, 2011). This is no doubt a possible view; yet we do not think that it undermines our conclusions about the (non) universality of harm norms. For, first, the 'Universal Moral Grammar' hypothesis is put forward by its advocates in a largely programmatic spirit. The stated aim is to explore "what a research program in moral cognition modeled on central features of Universal Grammar might look like” (Mikhail, 2011: 3), and to establish its "descriptive adequacy" in anticipation of future research. This makes it very difficult (at present, at least) to assess how empirically well-supported UMG in fact is, and hence whether it can provide materials for a causal premise in a Street-style EDA.

This leads to a second reason why UMG does not disrupt our conclusions. Locating the universal aspect of moral norms at the level of tacit cognitive machinery rather than overt (proto-)judgments, UMG seems closer to Joyce's causal premise, which we have discussed at length above. And indeed, Mikhail cites as "initial evidence" for the view much of the same findings that we considered as possible sources of support for Joyce's premise, including children's alleged ability to distinguish moral and conventional norms; the thought that moral processing occurs in a dedicated region(s) of the brain; and so on (Mikhail, 2011: 104-106). Now if, as we argue above, these findings do not support 
Joyce's causal premise as he actually states it, then equally they would not support a version of that premise which appealed to the selective emergence of moral grammar rather than moral concepts. ${ }^{14}$

Another potential candidate for a moral universal not to do with harming is some kind of norm of reciprocity. This is a broad category, so hard to pinpoint empirically. Experimental economists have recently tested tendencies towards reciprocity, in the context of strategy choice in games such as Dictator and Ultimatum. These experiments call upon individuals to choose how much of a contested good to demand for themselves and/or whether to accept an offer from another player. Ensminger and Henrich (2014) report tests conducted across a broad sample of societies, differing in size, economy type, religious character and other features. Substantial cross-cultural variation was detected, in both the type and size of offers participants were willing to make and/or accept. Similar results were found in a related Public Goods experiment (Henrich et al., 2005). Moreover, recent findings also suggest that a similar variability exists with respect to indirect reciprocity, where subjects take into account the behavior of a potential partner in interactions with third parties (Henrich et al., 2006). Together, these results show that reciprocity is indeed a common theme in diverse moral contexts. But they cast doubt on the idea of universal norms of reciprocity.

Street does not commit to the specific content or scope of moral universals; she mainly provides examples. So we cannot examine every possible norm she may want to invoke. But we think that if in the contexts just surveyed - paradigmatic and variegated as they are - one cannot find deep crosscultural commonalities, then it is unlikely that most (or even many) of our moral beliefs exhibit such commonalities. The plausibility of claiming that these beliefs are products of evolution by natural selection is correspondingly diminished.

\footnotetext{
${ }^{14}$ Our interest here in UMG comes of course from the possibility that it may (partly) explain how human morality evolved. It should be noted, however, that Mikhail himself refrains from endorsing this possibility. As he puts it, "we cannot seriously ask how moral knowledge ... evolved in the species until what constitutes moral knowledge and how it is acquired and put to use by each individual are better understood" (2011: 24).
} 
To summarize, the evidence seems to tell against a story such as Street's. Moral change occurs at a pace more compatible with cultural mechanisms; theoretical models of altruism are of limited explanatory value with respect to motivation and belief; and there is scant evidence for moral universals. Moreover, as we pointed out at the outset, the intuitive plausibility of Street's case seems to rest in part on her arguably tendentious choice of examples. Overall, the idea that natural selection shaped the content of our moral beliefs seems questionable.

\section{Conclusion}

If successful, the preceding discussion throws into doubt the causal premises of the two most prominent EDAs out there. This puts considerable pressure on aspiring debunkers: Unless and until a plausible alternative causal premise is put forward, EDAs offer little more than a promissory note. Can such a note be cashed out in ways not covered by the foregoing discussion? We are somewhat skeptical. In closing, let us briefly explain why.

Broadly speaking, there are two main options here. The debunker could either try to show how human morality was shaped by biological evolution; or alternatively, she could opt for an explanation involving some sort of cultural evolutionary process. Let us start with the former. This category includes, as we have seen, the thought that natural selection favored creatures who held beliefs with specific advantageous contents, as Street argues; or alternatively creatures who possessed the general capacity to form (advantageous) moral beliefs, as Joyce maintains. We have rejected both these options. But there is a third. When discussing Joyce's hypothesis, recall, we stressed the unlikelihood that a capacity to form specifically moral beliefs is an adaptation. But perhaps a more general normative capacity is. For example, one may seize on our earlier objection to Joyce that the sort of 'motivational bulwark' 
guarding against weakness of will, which he posits as the function of the moral capacity, seems equally useful in negotiating a range of similar conflicts in non-moral domains. This point, one may suggest, shows how natural selection explains the emergence of a human 'normative sense'. This would amount to a generalized version of Joyce's original hypothesis.

For reasons already noted, this proposal is cold comfort to Joyce himself and anyone sharing his commitments, as it would yield skepticism with respect to, besides moral, also epistemic and prudential normativity. However, Street's EDA is part of a more ambitious project of rejecting realist-style, mindindependent normativity in favor of meta-normative anti-realism. So she could welcome an evolutionary hypothesis that applies to normativity across the board.

However, it is far from obvious that the process by which a general normative capacity evolved would be off-track, as the epistemic premise states. Recall the example of an epistemically normative belief we provided when discussing Joyce's hypothesis: The belief that the dropping temperatures are reason to believe that inclement weather is impending. Such a belief, we suggested, could be considered advantageous inasmuch as it helps to ensure that one starts storing food for the period of inclement weather rather than succumbing to more immediate temptations and massaging the evidence. But at least prima facie, it seems the evolutionary advantages here actually depend on it being true that the dropping temperatures are in fact reason to believe that inclement weather is impending. Otherwise, creatures who held such beliefs would often enough expend their energy inefficiently, gathering and storing food when there is little point in doing so. ${ }^{15}$

A second way to develop an alternative causal premise draws on cultural rather than biological evolution. Roughly speaking, the process of cultural evolution shares key explanatory components

15 Parfit (2011, II: 488-498) makes a related point. Street (2009) defends a version of her EDA targeting epistemic reasons. We are not convinced by Street's argument, but do not have the space to examine it here. 
with biological evolution, invoking the notions of variation, selection, and inheritance in structurally similar ways. The primary difference is that cultural inheritance works via social learning rather than genetic transmission: Beliefs, customs, and behaviors are assumed to propagate via learning from parents, peers, and various role models.

As in the case of biological evolution, a key question that would have to be addressed in this context is whether the cultural evolution of moral beliefs, assuming it took place, is likely to have been off-track with respect to moral facts. 'Yes' is hardly the obvious answer. Social learning, the mechanism underlying cultural inheritance, may well be sensitive to truth-conducive properties of the learned information - such as consistency and evidential support. Moreover, it is plausible, as argued recently by Huemer (2016), that good learners (those who are good at tracking truth in general) tend to occupy positions of influence, for instance in culture and politics. For learning is correlated with other cognitive abilities such as language skills, strategic thinking etc., which may aid individuals in attaining positions of power and social influence - from which they could then propagate what they have learned. More generally, in many domains of knowledge - such as science, technology, and mathematics - social learning has arguably led humanity to epistemic successes. At least in part, this is likely due to the dynamics of social learning and to related social and institutional structures. The issues here are complex and merit deeper investigation, but as matters stand it is not clear that cultural evolution offers much solace to the debunker.

Finally, let us stress the following point. Our unfavorable assessment of evolutionary hypotheses does not, in our view, imply that moral realists are entirely off the hook. One may fairly point out that the burden of proof lies with the debunker to back up her claim that evolution explains human moral psychology. But whether or not the debunker manages to pull this off, her opponent would be in 
better stead if she can come up with a credible hypothesis of her own as to how human morality evolved (Fitzpatrick, 2014; Leibowitz and Sinclair, 2016). Determining which side is better placed to discharge these conflicting tasks requires engaging with the science far more seriously than has been done so far. Alongside critically examining the causal premises of existing EDAs, driving home this broader methodological point has been one of our aims in this paper.

\section{References}

Ayala, F.J. (2010), The difference of being human: Morality, Proceedings of the National Academy of Sciences 107: 9015-9022.

Bedke, M. (2014), No Coincidence?, in Shafer-Landau (Ed.) Oxford Studies in Metaethics, Vol. 9. Oxford University Press.

Berker, S. (2009), The normative (in)significance of neuroscience, Philosophy and Public Affairs, 37(4): 293-329.

Bourke, A.F.G. (2011), Principles of Social Evolution. Oxford University Press.

Carruthers P., James S. (2008). Evolution and the Possibility of Moral Realism, Philosophy and Phenomenological Research 77: 237-244.

Copp, D. (2008), Darwinian Skepticism about Moral Realism, Philosophical Issues, 18(1): 186-206.

Dennett, D. (1995), Darwin's Dangerous Idea. NY: Simon \& Schuster.

Ensminger, J. and Henrich, J. (Eds., 2014), Experimenting with Social Norms: Fairness and Punishment in CrossCultural Perspective. Russel Sage Foundation.

Fitzpatrick, W. (2014), Why There is No Darwinian Dilemma for Ethical Realism, in M. Bergmann and P. Kain eds., Challenges to Moral and Religious Belief: Disagreement and Evolution. Oxford University Press.

Fitzpatrick, W. (2015), Scientific Naturalism and the Explanation of Moral Beliefs: Challenging Evolutionary Debunking, in Kelly Clark, ed., A Companion to Naturalism. London: Blackwell.

Greene, J.D. (2014), Beyond Point-and-Shoot Morality: Why Cognitive (Neuro)Science Matters for Ethics. Ethics 124(4): 695-726.

Haidt, J., Koller, S. and Dias, M. (1993). Affect, culture and morality, or is it wrong to eat your dog? Journal of Personality and Social Psychology, 65: 613-628.

Hauser, M. (2006). Moral Minds. New York: Ecco Press.

Henrich, J., Boyd, R., Bowles, S., Camerer, C., Fehr, E., Gintis, H., McElreath, R., et al. (2005). "Economic man" in cross-cultural perspective: Behavioral experiments in 15 small-scale societies. Behavioral and Brain Sciences , 28, 795-855. 
Henrich, J., McElreath, R., Ensminger, J., Barr, A., Barrett, C., Bolyanatz, A., Cardenas, J. C., et al. (2006). Costly Punishment Across Human Societies. Science, 312, 1767-1770.

Huemer, M. (2016), A liberal realist answer to debunking skeptics: the empirical case for realism. Philosophical Studies, 173: 1983-2010.

Isserow, J. (2018), Evolutionary Hypotheses and Moral Skepticism. Erkenntnis.

https://doi.org/10.1007/s10670-018-9993-8

Joyce, R. (2005) “Moral fictionalism.” In M. Kalderon (ed.), Fictionalism in Metaphysics. Oxford University Press.

Joyce, R. (2006), The Evolution of Morality. MIT Press.

Joyce R. (2016a), Evolution, truth-tracking, and moral skepticism. In his Essays in Moral Skepticism. Oxford University Press.

Joyce, R. (2016b), Reply: Confessions of a Modest Debunker. In: Leibowitz U.D. and Sinclair, N. (Eds.), Explanation in Ethics and Mathematics. Oxford University Press.

Kahane, G. (2011), Evolutionary Debunking Arguments, Noûs 45: 103-125.

Kitcher, P. (2011), The Ethical Project. Cambridge, MA: Harvard University Press.

Israel, S., Hasenfratz, L. and Kanfo, A. (2015), The genetics of morality and prosociality. Current Opinion in Psychology 6: 55-59.

Leibowitz, U. D. and Sinclair, N. (2017), Evolution and the Missing Link (in Debunking Arguments).

Forthcoming in Ruse and Richards (eds.), Cambridge Handbook to Evolutionary Etbics.

Levy, A. (2011), Game Theory, Indirect Modelling, and the Origins of Morality. Journal of Philosophy, CVII: 171187.

Machery, E., and Mallon, R. (2010), Evolution of morality. In J. M. Doris and the Moral Psychology Research Group (Eds.), The Moral Psychology Handbook. Oxford University Press.

Mikhail, J. (2011). Elements of Moral Cognition: Rawls' Linguistic Analogy and the Cognitive Science of Moral and Legal Judgment. New York: Cambridge University Press.

Moll, J., R. Zahn, M. Pardini, R. de Oliveira-Souza, and J. Grafhian 2005. The Neural Basis of Human Moral Cognition. Nature Reviews Neuroscience 6: 799-809.

Nichols, S. (2002), Norms with feeling: Toward a psychological account of moral judgment. Cognition 84: 223236.

Nichols, S. (2004), Sentimental Rules: On the Natural Foundations of Moral Judgment. Oxford University Press.

Nisan, M. (1987), Moral norms and social conventions: A cross-cultural comparison. Developmental Psychology, 23: 719-725.

Nowak M. A. (2006), Evolutionary Dynamics: Exploring the Equations of Life. Harvard University Press.

Nucci, L. (2001), Education in the Moral Domain. Cambridge: Cambridge University Press.

Nucci, L. and Turiel, E. (1978), Social interactions and the development of social concepts in preschool children. Child Development 49: 400-407. 
Okasha, S. (2013), Biological Altruism. The Stanford Encyclopedia of Philosophy (Fall 2013 Edition), Edward N. Zalta (ed.), URL $=<$ http://plato.stanford.edu/archives/fall2013/entries/altruism-biological/>.

Parfit, D. (2011), On What Matters. Oxford University Press.

Parkinson, C, W. Sinnott-Armstrong, P. Koralus, A. Mendelovici, V. McGeer, and T. Wheatley (2011). "Is Morality Unified? Evidence that Distinct Neural Systems Underlie Moral Judgments of Harm, Dishonesty, and Disgust," Journal of Cognitive Neuroscience 23(10): 3162-80

Pölzler, T. (2018), Moral Reality and the Empirical Sciences. New York: Routledge.

Prinz, J.J. (2007), Is Morality Innate? in W. Sinnott-Armstrong (ed.), Moral Psychology, Vol. 1: 367-407.

Shor, E and Simchai, D. (2009), Incest Avoidance, the Incest Taboo, and Social Cohesion: Revisiting Westermarck and the Case of the Israeli Kibbutzim. American Journal of Sociology. 114 (6): 1803-1842.

Sinnott-Armstrong, W. and Wheatley, T. (2012), The Disunity of Morality and why it Matters to Philosophy. The Monist, 95(3): 355-377.

Skyrms, B. (2003), The Stag Hunt and the Evolution of Social Structure, Cambridge University Press.

Smetana, J. (1981), Preschool children's conceptions of moral and social rules. Child Development 52: 1333-1336.

Smith, K.B., Alford, J.R., Hibbing, J.R., Martin, N.G., Hatemi, P.K. (2016), Intuitive Ethics and Political Orientations: Testing Moral Foundations as a Theory of Political Ideology, American Journal of Political Science.

Sripada, C.S. (2007), Nativism and Moral Psychology: Three Models of the Innate Structure that Shapes the Content of Moral Norms. in W. Sinnott-Armstrong (ed.), Moral Psychology, Vol. 1: 319-344.

Sterelny, K. (2012), The Evolved Apprentice. Cambridge, MA: MIT Press.

Street, S. (2006), A Darwinian dilemma for realist theories of value. Philosophical Studies 127: 109-166.

Street, S. (2009) Evolution and the Normativity of Epistemic Reasons. Canadian Journal of Pbilosopby 39:213-248

Thorhill, N.W. (1990), The Evolutionary Significance of Incest Rules, Ethology and Sociobiology 11(2) 113-129.

Thornhill, N.W. (1991), An Evolutionary Analysis of Rules Regulating Human Inbreeding and Marriage. Behavioral and Brain Sciences, 14(2) :247-261.

Tisak, M. (1995), Domains of social reasoning and beyond. In R. Vasta (ed.), Annals of Child Development, Vol. 11. London: Jessica Kingsley.

Tisak, M.S. and Turiel, E. (1984), Variation in seriousness of transgressions and children's moral and conventional concepts. Developmental Psychology 24(3): 352-357

Trivers, R. L. (1971), The Evolution of Reciprocal Altruism. The Quarterly Review of Biology 46(1): 35-57

Trivers, R. L. (1974), Parent-Offspring Conflict. American Zoologist 14(1): 249-264.

Vavova, K. (2015), Evolutionary Debunking of Moral Realism, Philosophy Compass 10(2): 104-116.

Weibull, J. (1995), Evolutionary Game Theory. Cambridge, MA: MIT Press.

White, R. (2010), You Just Believe that Because... Philosophical Perspectives 24: 573-615. 